\title{
Mini-invasive and innovative cardiac surgery conference devoted to the memory of Isa K. Akhunbaev
}

Taalaibek Z. Kudaiberdiev' ${ }^{1}$, Zhamalbek I. Ashimov ${ }^{1}$, Stalbek M.Akhunbaev², Seitkhan D, Djoshibaev ${ }^{3,4}$, Boris M. Todurov ${ }^{5}$, Talant K. Arstankulov ${ }^{6}$, Arthur B. Jumanazarov ${ }^{7}$

${ }^{1}$ SRI of Heart, Surgery and Organ Transplantation, Bishkek, Kyrgyzstan

${ }^{2}$ International Higher School of Medicine, Bishkek, Kyrgyzstan

${ }^{3}$ Euro-Asian Association of CardioThoracic Surgeons, EAACTS

${ }^{4}$ Scientific-Clinical Center of Cardiac Surgery and Transplantation, Taraz, Kazakhstan

${ }^{5}$ Heart Institute, Kiev, Ukraine

${ }^{6}$ Osh Oblast Clinical Hospital, Osh, Kyrgyzstan

${ }^{7}$ Ministry of Health and Social Development of Kyrgyz Republic

The $4^{\text {th }}$ Annual Scientific-Practical Conference on Miniinvasive and Innovative Cardiac Surgery devoted to the memory of Isa K. Akhunbaev was held between 19-22 June 2021, in Bishkek and Baet, Issyk-Kul, Kyrgyzstan.

The conference was organized by SRI of Heart, Surgery and Organ Transplantation, Bishkek, Kyrgyzstan, International Higher School of Medicine, Bishkek,
Kyrgyzstan and Euro-Asian Association of CardioThoracic Surgeons with participation of Heart Institute, Kiev, Ukraine, Scientific-Clinical Center of Cardiac Surgery and Transplantation, Taraz, Kazakhstan and Osh Oblast Clinical Hospital, Osh, Kyrgyzstan and support Ministry of Health and Social Development of Kyrgyz Republic.

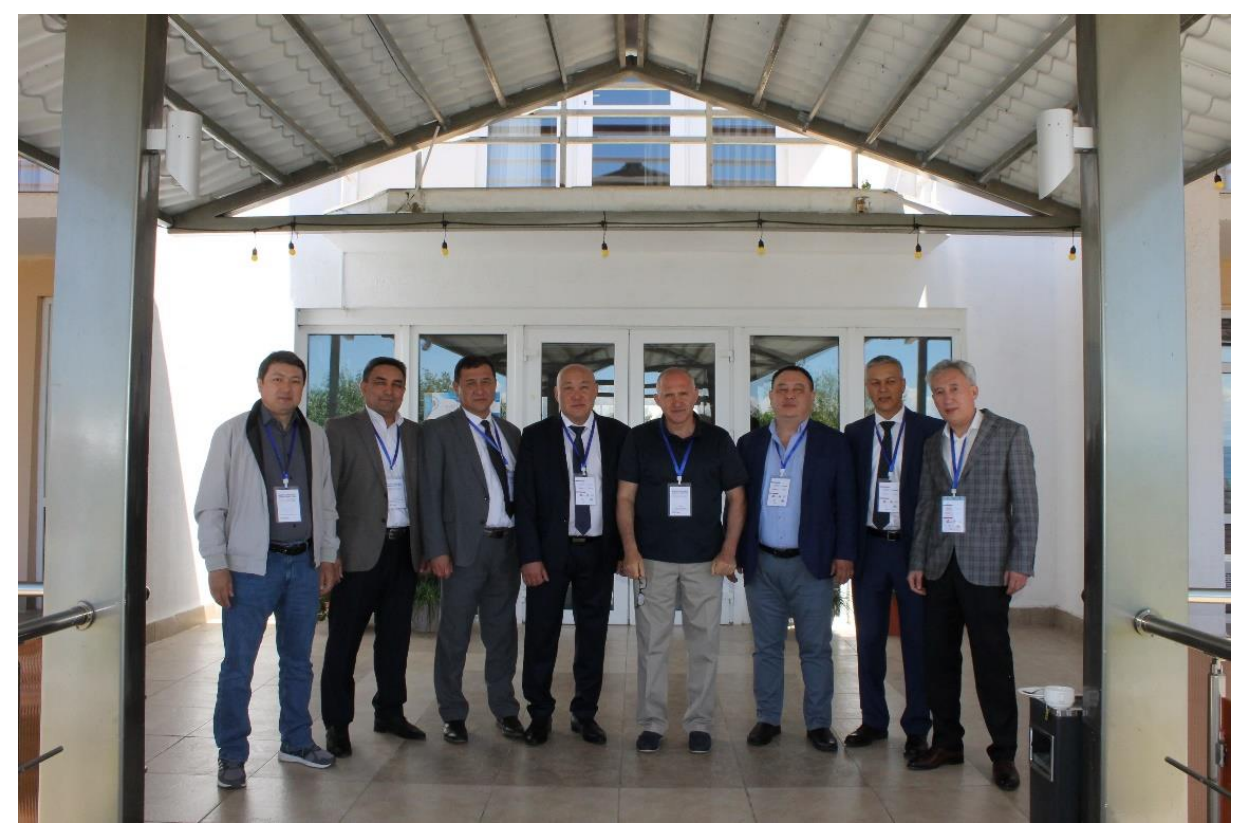

Figure 1. Conference faculty and organizers: from right to left - Emil Aliev, Dolon Aripov, Taalaibek Z. Kudaiberdiev (SRI Heart Surgery and Organ Transplantation, Bishkek, Kyrgyzstan), Boris Todurov (Heart Institute, Kiev, Ukraine), Arthur Jumanazarov (Ministry of Health and Social Development of Kyrgyz Republic, Bishkek, Kyrgyzstan), Stalbek M. Akhunbaev (International Higher School of Medicine, Bishkek, Kyrgyzstan), Talant K. Arstankulov, Adil Diyanbaev (Osh Oblast Clinical Hospital, Osh, Kyrgyzstan)

Address for Correspondence: Taalaibek Z. Kudaiberdiev, SRI of Heart Surgery and Organ Transplantation, Bishkek, Kyrgyzstan, Email: tkudaiberdiev@gmail.com

Received: 01.06.2021 Accepted: 02..06.202 
Heart, Vessels and Transplantation 2021; 5: doi: 10.24969/hvt.2020.252

In frame of conference, practical master-classes on exchange of experience between Ukranian, Kazakhstan and Kyrgyzstan cardiac surgeons were implemented under lead of Boris Todurov (Ukraine), Jalil Sheishenov (Kazakhstan) and Zhamalbek Ashimov (Kyrgyzstan) at SRI of Heart Surgery and Organ Transplantation in
Bishkek, Kyrgyzstan. The following cardiac surgery procedures as mini-invasive and thoracoscopic closure of septal defects in congenital heart diseases, Ozaki procedure for aortic valve repair surgery, Bentall de Bono repair of aortic valve and ascending aorta and valve replacement surgeries were performed (Fig. 2).

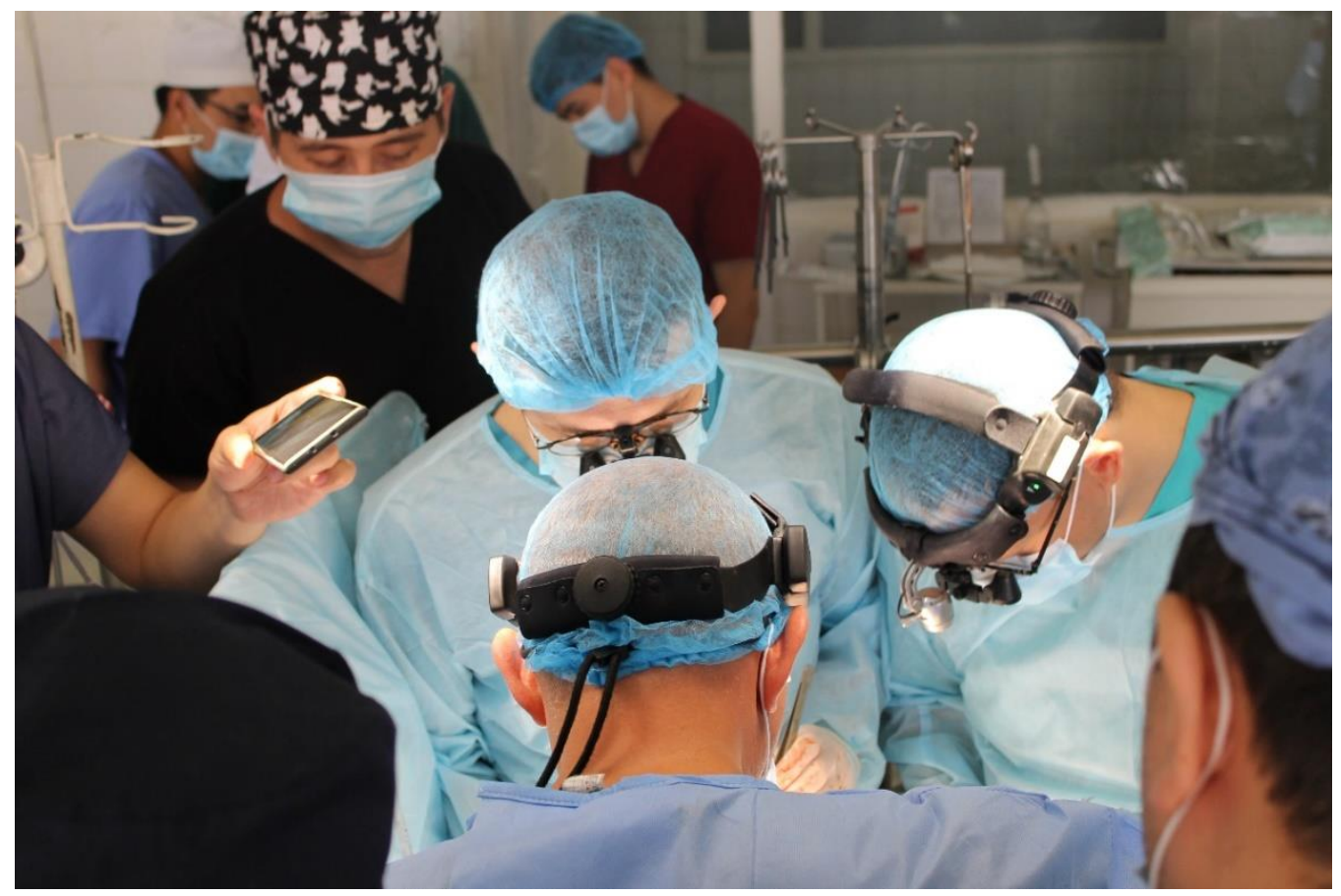

a)

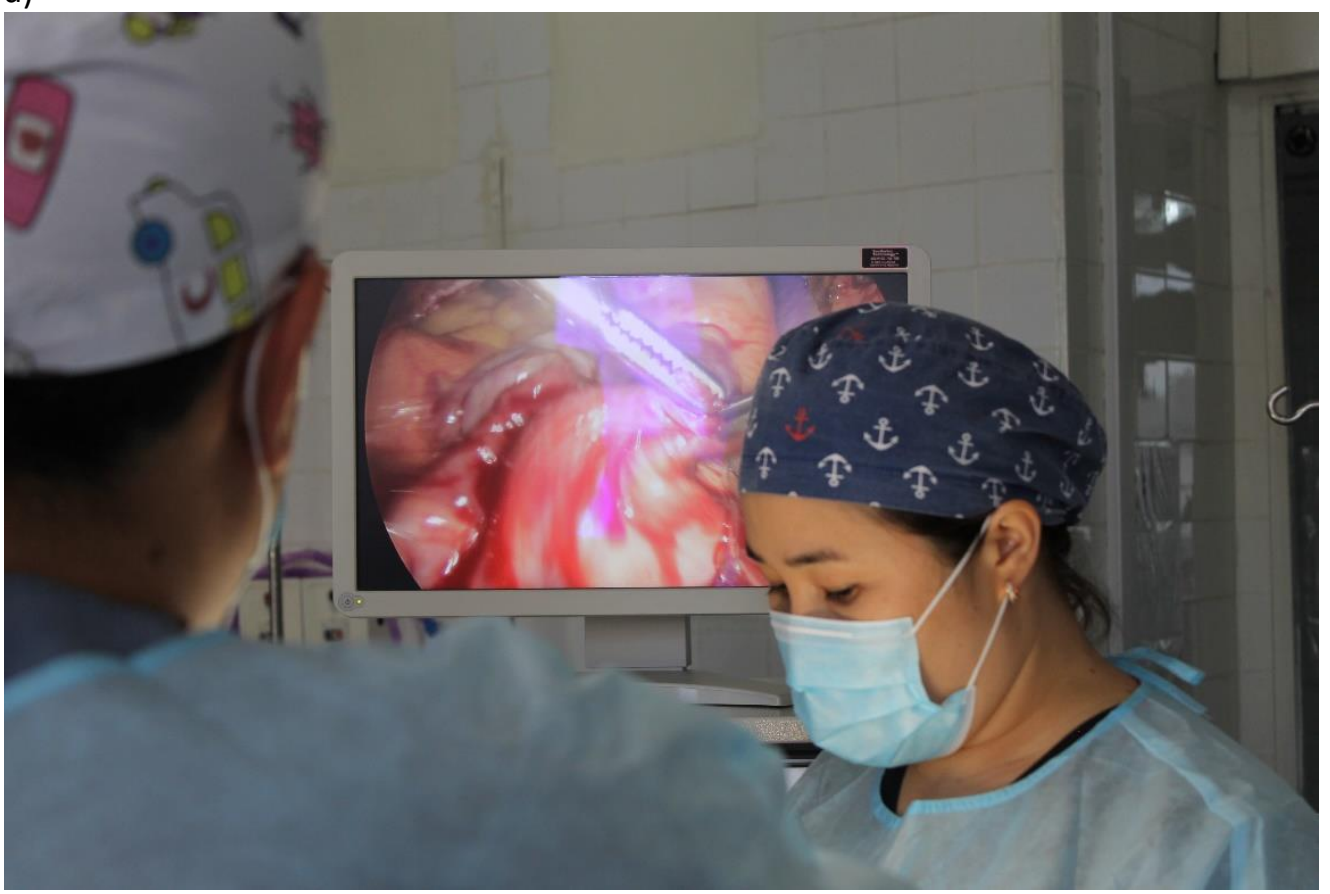

b) 


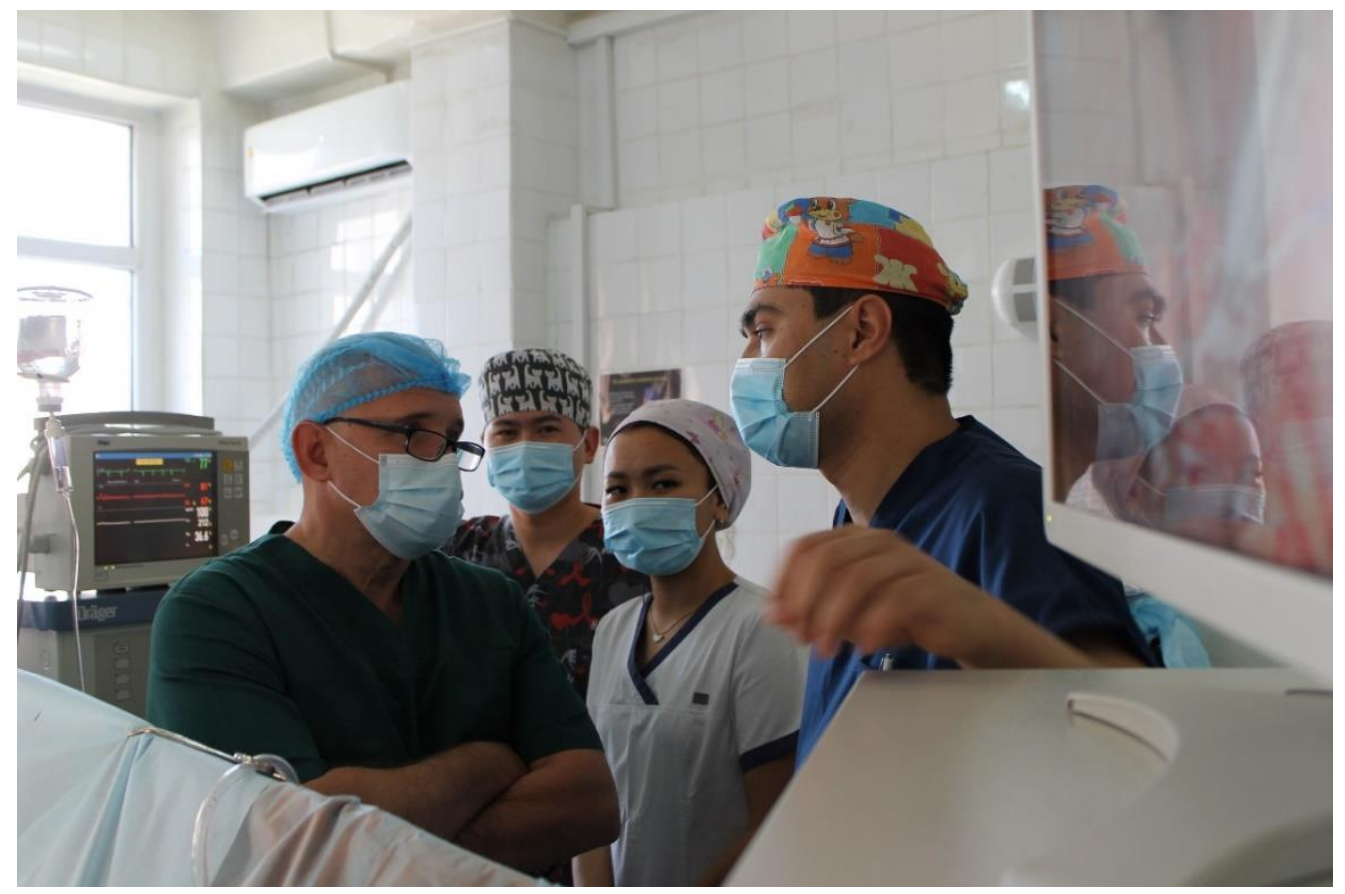

c)

Figure 2. Joint master-class cardiac surgery operations by Ukranian, Kazakhstan and Kyrgyzstan surgeons

Important, actual and emergent directions of the development of cardiac surgery fields as mini-invasive cardiac surgery and surgery of chronic heart failure were discussed and experience was shared during scientific part of conference at Baet, Issyk-Kul (Fig. 3).

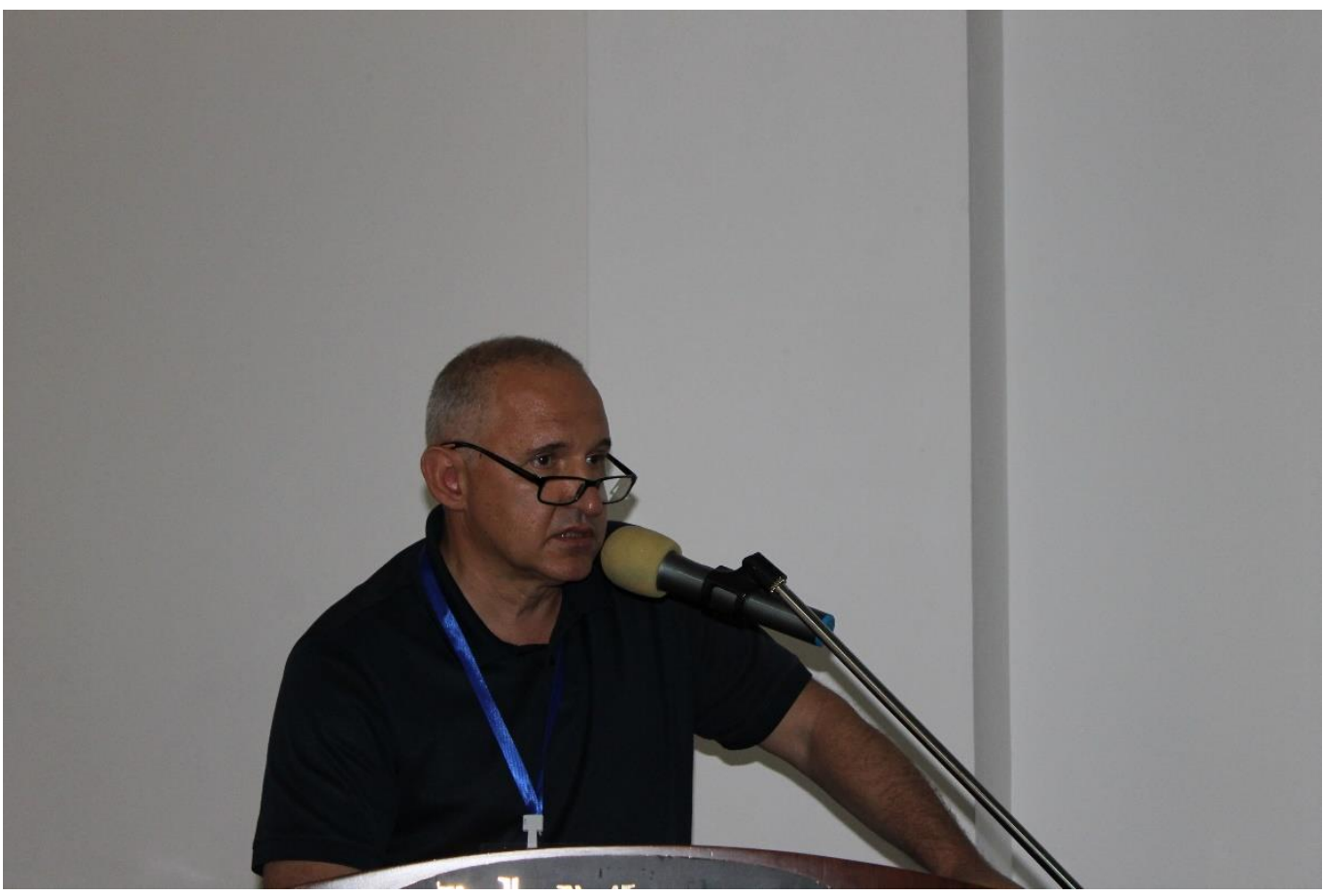

Figure 3. Lecture by Boris Todurov, Heart, Institute, Kiev, Ukraine 
Clinical and official parts of conference were concluded by the signing of memorandum of cooperation between Heart Institute, Kiev Ukraine, represented by Boris Todurov, SRI Institute of Heart Surgery and Organ
Transplantation -Zhamalbek

Ashimov, Bishkek, Kyrgyzstan and Osh Oblast Clinical Hospital, Osh, Kyrgyzstan -Talant K.Arstankulov (Fig. 4).

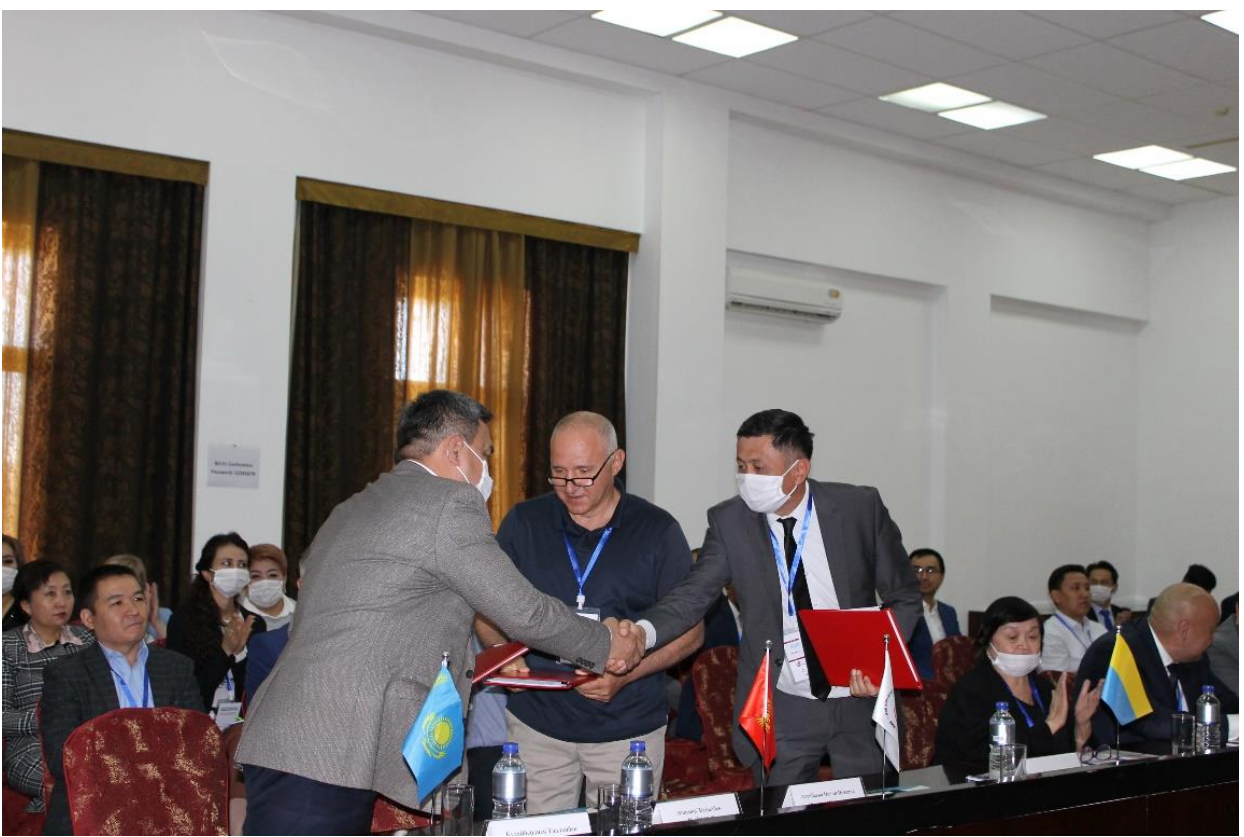

Figure 4. Official ceremony of Memorandum of Cooperation between Heart Institute, Kiev, Ukraine - Boris Todurov, Ukraine, SRI of Heart Surgery and Organ Transplantation - Zhamal Ashimov, Bishkek, Kyrgyzstan and Osh Oblast Clinical Hospital, Osh, Kyrgyzstan

More than 100 specialists in cardiac surgery, cardiology, anesthesiology, reanimatology, functional diagnostics, arrhythmology and interventional surgery took part in the conference.
Conference finished with the Annual Biking Tour with attendance of conference participants from different countries (Fig. 5).

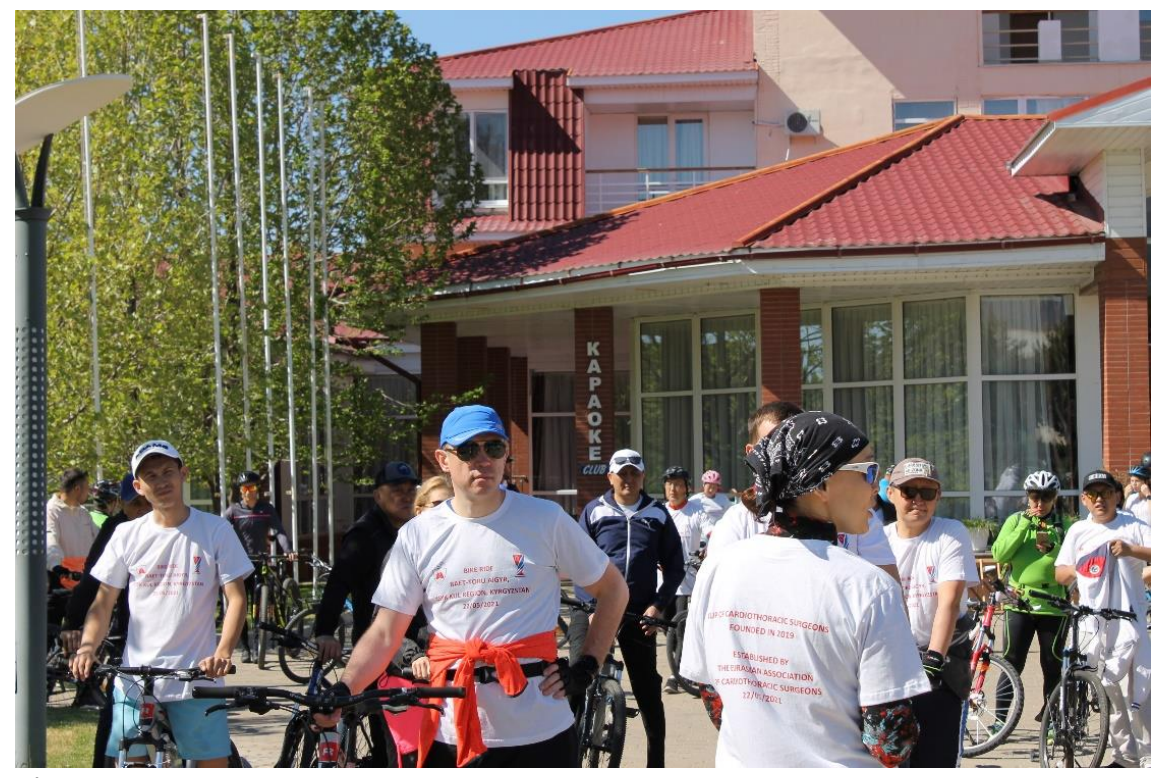

a) 


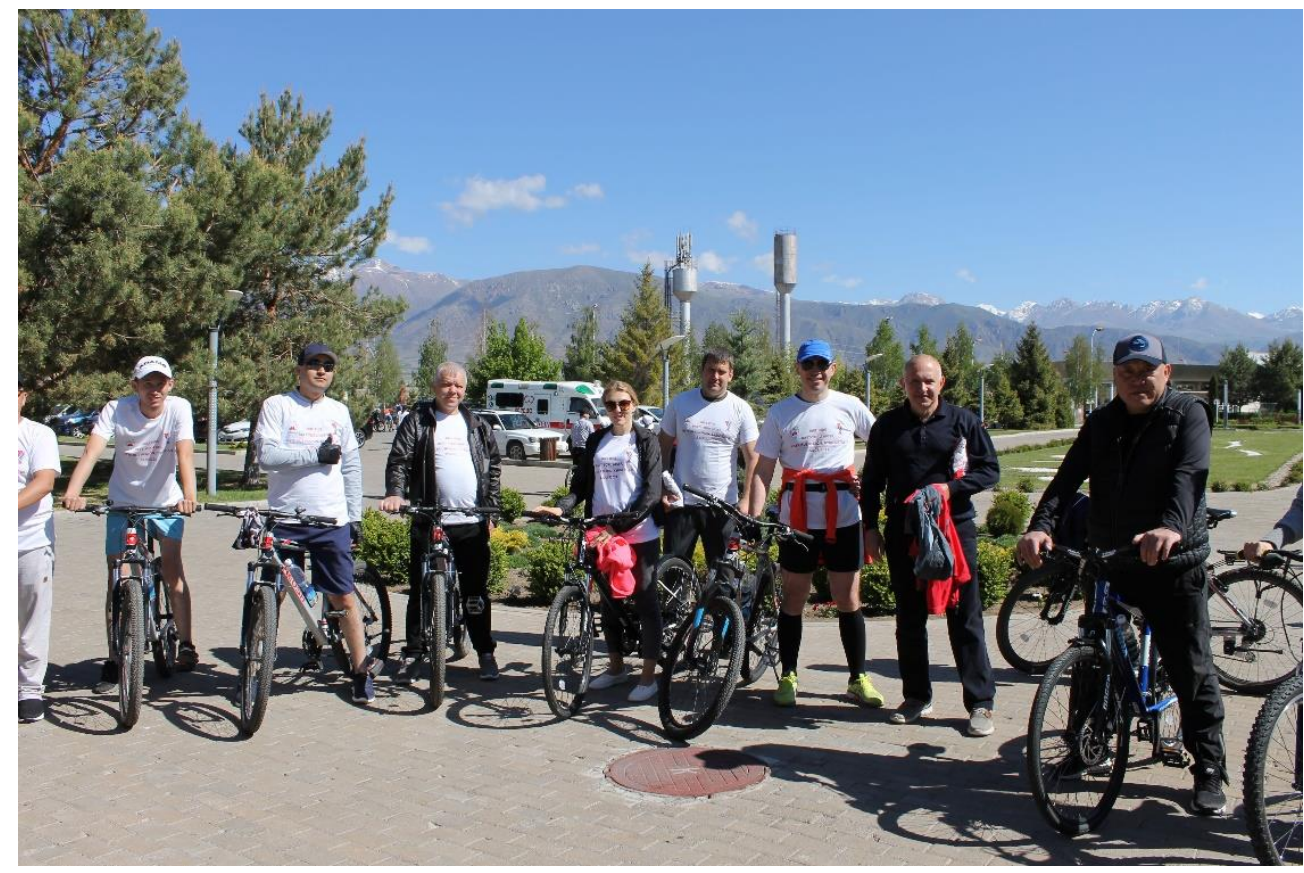

b)

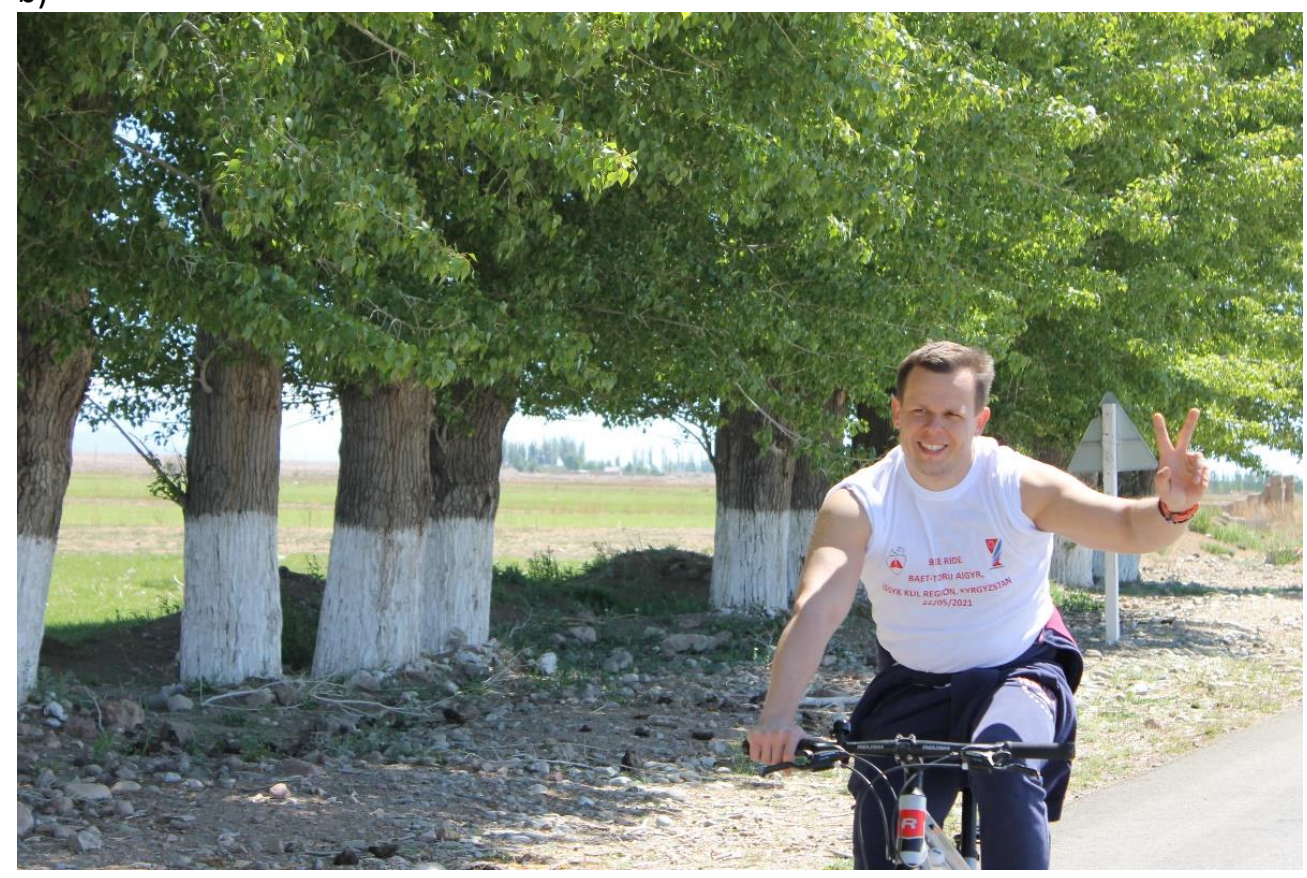

c)

Figure 5. Annual IK Akhunbaev Conference Biking Tour of faculty and participants at Baet - Toru Aygir, Issyk-Kul lake 2021.

Conflict of interest: None to declare Peer-review: Internal

Authorship: T.Z.K., S.M.A., S.D.D., B.M.T., T.K.A., and A.B.J. are equally contributed to preparation of manuscript and fulfilled authorship criteria Acknowledgement and funding: None to declare 
